\title{
AN INQUIRY
}

\section{INTO THE ORIGIN AND NATURE}

\author{
OF THE
}

\section{YELLOW FEVER,}

AS IT HAS LATELY APPEARED IN THE WEST INDIES,

$$
\text { WITH }
$$

\section{OFFICIAL DOCUMENTS}

RELATING TO

THIS SUBJECT.

BY WILLIAM FERGUSSON, M.D.

INSPECTOR OF HOSPITALS, AND PRINCTPAT, MEDICAL OFFICER IN THE LEEWARD AND WINDWARD ISRANDS.

\section{Read March 18, 1817.}

AS an introduction to the subject, which I propose to discuss in the present communication, I shall beg leave to premise the following queries, which were put by the Army Medical Board, in consequence of the great sickness and considerable mortality that prevailed on board some ships, conveying black recruits from Goree to the West Indies. 
NATURE AND ORIGN OF THE YRLLOW FEVER. 109

Barbadoes, October, 1816.

Queries relative to the Regalia Transport, which sailed with black recruits from the coast of Africa, for the West Indies, in 1815.

1. Was the ship good and her crew healthy before the blacks were embarked?
1. The ship was good and her crew healthy, until she took on board a large quantity of green wood, a very short time before the blacks were embarked.

2. What was the state of the black recruits? Who inspected them previously to embarkation? and from whence cid they come?
2. Many were embarked sick from hospital, with ulcers, fluxes, \&c. It is supposed they were inspected by the surgeon who had been appointed to accompany them, but did not, on account of sickness. No account can be obtained of the tribes or nations to which they belonged, previous to their capture at sea, or their being brought to Sierra Leone. 
3. Do you conceive that any thing in the ship, or in the state of her cargo, could have profever on her passage to the West Indies? duced a very destructive

3. A quantity of green wood, recently laid in on the coast of Africa, and foul ballasting that had not been changed for years, I conceive perfectly adequate to the production of the most destructive fever, under various modifications of leakage in any ship navigating the tropical seas.

4. Inform me as far as you can yourself learn, of the treatment of the black recruits, before and after their embarkation, their diet, exercise, \&c.
4. They had no surgeon to attend them in any of their own transports, and could not possibly be properly attended by the surgeon of the convoy ship, however ardently active might have been his disposition so to do, nor was it possible to furnish the transports with medicines and dressings as they might be wanted from that ship, supposing her to be furnished 
with supplies for such a service, which she could not possibly be at Sierra Leone, where the want of medical stores was assigned as a reason for sending sick from the hospitals to the ships. Their diet was not suitable either in the provision laid in, or distribution afterwards, as was. proved to the Military Board that sat at Barbadoes, to inquire into the causes of the sickness and mortality on the passage.

5. The description of these recruits, whether young or old, and their previous habits and occu. pations, in as far as you can learn them?

6. Inform me of the number sick on arrival at Barbadoes, and describe particularly the disease under which they labour- masia. The treatment
5. They were mostly very young. Their description that of uncivilized Africans. Some of them of a very barbarous description.

6. 114 sick labouring principally under dysentery, ulcers, and dropsy, or cachectic leucophleg- 
ed, with the different of the first was conductmodes of treatment which ed by mercurials, ipecawere pursued? _. cuanha, lime juice, and the mucilages ; of the second by stimulating antiseptic dressings, combined with a generous antiscorbutic diet; and the third by deobstruents, tonics, stimulants, diuretics, \&c.

7. I request to know the total number sick on

7. The convoy ship the passage, with the number of deaths, and the number sent sick on shore? did not come into Barbadoes, therefore no communication could be held with the surgeon to ascertain the number of sick on the passage. The number of deaths was 52 ; the number sent sick on shore to hospitals 114 .

8. I request to know the strength of the detachment when embarked at Sierra Leone; the strength when landed at Barbadoes, and the number sick on arrival at Barbadoes? 
9. I beg to be inform- 9. The number that ed of the result in the perished in hospital in number landed at Bar - the course of 2 months, badoes, and the present from 24th of August to state of the detachment? 24th of October, was 70, (Signed) viz. 53 of fluxes, 5 of "J. M'Grigor," dropsy, 9 of pulmonic Director General." complaints, 1 of ulcer, and 2 of fever.

The : number treated 288. There was no case of elephantiasis or unmixed scurvy seen amongst the recruits landed at Barbadoes. :

(Signed)

$$
\text { W. Fergusson, }
$$

Inspector of Hospitals.

In replying to the foregoing queries I have confined myself entirely to the points which I was directed to answer; but as the circumstances of health under which the crew and the inmates of the Regalia Transport arrived at Barbadoes, present an interesting field of investigation in regard to the infectious nature of tropical fever and dysentery, I have considered it my duty to throw every light in my power on this long disputed and yet undecided question.

vox. vini. 
- From the documents that will be produced as an Appendix at the conclusion of this paper, it will be seen that the Regalia Transport arrived at Barbadoes in the month of August 1815, with the yellow fever on board from the coast of Guinea, its supposed original source : that the ship on her arrival at Barbadoes was not put under any restraint or quarantine*, but communicated freely with the sea-ports of Barbadoes, the Saints, Antigua, and Guadaloupe; landing the severely ill or dying subjects of that disease amongst the inhabitants and at the hospitals at Barbadoes and Antigua, without communicating any infection at any of these places $\dagger$; and finally, after having undergone a thorough purification, sailing from Guadaloupe for Europe, crowded to a very great degree with rebel French prisoners and their families from the jails under the most dangerous circumstances to health, with a case of yellow fever actually dying on board $\ddagger$ the day before she left Basseterre Roads II, but without communicating any such fevers to the unfortunate passengers, leaving any behind her at Guadaloupe, or importing any at the ports she ultimately reached.

* This happened through oversight of the Inspecting Medical Officer, while the army was absent at Guadaloupe.

$\uparrow$ Vide Appendices, Nos. 1, 2, and 3. \$ Vide Appendix, No. 4.

|| I was absent from Basseterre at the time the Regalia arrived, and did not return till after she had sailed.-She was there only two days. 
The first yellow fevers that were heard of there occurred at least five months afterwards, amongst some civilian strangers newly arrived from Old France, and these, while the British retained possession of the island, never extended to the seasoned inhabitants and troops in garrison, with the exception of some white officers of the black corps, that garrisoned Point au Pitre, who, on the very evacuation of that place, not so much as three months ago, were seized with yellow fever, and died of it in Saint Vincent.

In like manner it will be seen from the queries prefixed, and the sick returns of that period, that a most putrid and malignant dysentery was introduced into, and filled our hospitals at Barbadoes, from the negroes that the Regalia imported; but that the disease did not in a single instance infect any medical attendant or servant employed about the sick.

As the question will next naturally arise, how such a fever as that which destroyed so many of the crew of the Regalia, and attacked almost every one that came on board of her to supply the place of those that had perished, could spread so unerringly and prove so destructive without being infectious, I shall enter into it more at length.

The quantity of green wood laid in at Sierra Leone on board the Regalia for fuel, must have 
been very considerable; for after she had been several weeks in the West Indies, there were still as many tons of it left as in the master's opinion would serve for a voyage to Europe. The ballast too had never been changed or shifted from the time she left England, nor for any discoverable time before. It was what is called shingle ballast, small stones with a considerable mixture of mud and other impurities; and when I examined it on board the Regalia, it had been much fouled by leakage from the water casks. The ship in respect to leakage was far from being a dry ship*, and from that circumstance might, with better ballast (of iron or large stones) have proved a very healthy one; but the absorption of sea water amongst foul ballast and green wood, could scarcely fail to prove unwholesome. In other respects the Regalia, in all her apartments of cabin, steerage, and betwixt decks, was uncommonly lofty and well aired, and so far from being crowded, she had about double the tonnage for the complement of negroes she brought over that is commonly. allowed for troops. She was excellently found in every species of provisions and stores, and her discipline and cleanliness were unobjectionable. In short, there was nothing in her nor about her that could either generate or permit the retention, if introduced, of the matter of typhous fever. The cause

* She had 32 inches of water in the well at the time I sounded it, and, according to the master's calculation, she made three quarters of an inch every hour. 
of disease was therefore, I am clearly of opinion, to be ascribed to the green wood laid in at Sierra Leone, operating along with the foul ballast to furnish, when impregnated with the gases arising from putrid sea water, morbific miasmata, similar to those that on land arise from marshes when exposed to the influence of the higher degrees of atmospherical heat. Why this morbific power operated differently on the blacks and the whites, may be explained from the fact that the African is very rarely amenable to those influences that affect white men with intermittent, remittent or yellow fevers. If they operated at all therefore on them, they must have produced some other disease; but I see no reason to attribute the dysentery of the blacks from which so many perished *, to other causes than those that have been proved to exist, viz: the sending numbers from the hospitals of Sierra Leone to the ships ill with that disease, the want of proper remedies and medical attendance during the voyage, and the highly improper and dangerous change of diet, from one wholly vegetable to the ordinary ship's rations, which, on board the Regalia particularly, were served to those poor creatures during the voyaget. They were

- One hundred and eleven fluxes were received into hospital, independently of those that died on the passage, 53 of whom (very nearly one half) perished.

+ Vide Report to the commander of the forces, founded on the evidence produced before the Medical Board of Officers that sat at Barbadoes, a copy of which was sent to the Medical Board, dated 28th September, 1815. 
received into our hospitals without any extraordinary precaution, fear, or scruple: for though the medical schools of Europe have raved for centuries about the contagion of dysentery, of which, as their professors seldom served in armies or lived amongst organized bodies of men, they could know very little; every regimental surgeon who has served a campaign, or surgeon of a militia regiment who has been in an autumnal encampment on any of the downs of England, knows well that however practicable it may be, through an undue accumulation of sick, and neglect of cleanliness and ventilation, to propagate a typhoid contagion under the leading form and features of dysentery, ulcer, pneumonia, \&c., dysentery itself under all ordinary circumstances of accommodation, is no more an infectious disease than hæmorrhoids or catarrh.

In regard to the contagion of yellow fever, all those the best qualified to judge, that is to say, those who have spent their lives and devoted their services in the countries between the tropics, where it is so often present, are of the same opinion. I do not pretend to say that amidst the heterogeneous mixture of which our profession is composed, $I$ have not heard some profess and even subscribe to a different belief; but I can declare that I never knew a single instance of any one, provided he had had experience of the disease, acting as if he believed in its being contagious, or taking any of the precautions which the instinct of fear or the smallest degree of common prudence would in that case 
have dictated. He was contented with voting himself contagion proof, and never scrupled to inhale the breath, or repose within the atmosphere, of the dying patient. This question, hitherto so far from being decided, that it has lately been agitated in no common degree, by the writings of two men of rank and talents in the profession, deeply affects the peace, and involves the best interests of society. I know nothing of the field on which they have written, for I have never been at Gibraltar or Cadiz. The reports of the army and my own inspection reports*, written before even I heard of any of the before-mentioned works, will prove that the barracks of Fort Royal are the most unwholesome in the West Indies, and that they have uniformly proved destructive to every white regiment that has ventured to inhabit them, however well seasoned they may have been to the climate. This was evident very lately the case with the 15 th regiment, which has now been eleven years in the West Indies, and is one of the best seasoned corps. At Barbadoes they were very healthy, having almost no complaint amongst them except an ophthalmia, which there was great reason to believe was spurious. In the month of June last, they were sent down to take the duty of Fort Royal, preparatory to giving up the island of Martinique to the French. Part of them occupied the barracks alluded to by $\mathrm{Mr}$.

* Vide Report on Martinico, dated 12th September, 1815, and Appendices, Nos. 5 and 6. 
Pym, but not the low Bomb-proofs, and were detained there ten weeks. At first they were as healthy as usual, but towards the end of that period, they became so affected with remittent fevers as to be nearly unfit for service *; the proportion of fevers amongst that part of the corps being more than four to one, compared with the other wing of the regiment in Fort Bourbon on the hill. The sickly season had not then set fairly in, but had they continued at Fort Royal to the present time, there can scarcely be a doubt from their suffering so early and so severely, that before now they would, like other regiments in former times, have been nearly extirpated. The fort (Fort Edward, now Fort Louis) where the troops are quartered, has not only all the disadvantages of being situated on a leeward fenny shore, far down in a deep bay, but the additional ones of being at the mouth of the unwholesome carinage within pistol shot of its foulest banks, with several main trunks of profound uncleared ravines opening directly upon it from the country, and the extensive lamentine swamps in a great degree to windward of it, which, though four miles off, communicate directly with Port Royal, by a deep marginal continuous line of swamp along the shore.

That even black troops suffered from the same cause, was evident from the case of the 8 th West

- Viele Appendix, No. 12. 
India regiment, inhabiting the very Bomb-proofs from which the infection is reported to have spread in the year 1793, and who were attacked in the September of last year*, with a fever (little liable as these people are to that species of disease) differing scarcely any thing from the worst yellow fever of the whites. I can prove from my own inspections, and that of the deputy inspector lately stationed there, that Case Pilote, so far from being the healthy village represented by $\mathrm{Mr}$. Pym, is one where no new regiment could possibly remain healthy; as it is low, to leeward, on the level of the sea, at the mouth of a ravine with marshy ground near it in the same ravine, and high mountains behind it, that obstruct every breeze, and reverberate the rays of the sun with a force that makes it one of the hottest places I ever saw. I am sure that the enlightened author of that work, with whatever eyes he may have viewed it twentythree years ago, would not now venture to sleep. there if he could help it, for a single night in the hot season; at least I am sure that no other medical man experienced in these climates would: for, setting aside the peculiar unwholesomeness of Case Pilote, from its being in the mouth of a ravine, there is not one single spot at the level of the sea on the whole leeward shores, either of Martinique or Guadaloupet, where a new regiment could be en-

* Vide Monthly Sick Report for that period.

+ Vide Inspection Report on Guadaloupe. 
camped during the hot season, without being destroyed by tropical fevers; more particularly if, like the regiment in question, they had just come from active service in the field; a juncture, which is ever trying to the health of troops in the purest climates and the best quarters.

One thing is certain about Case Pilote, that if the 7oth regiment carried the infection of yellow fever in Mr. Pym's time, they left none of it behind them amongst the inhabitants; as has been proved by the evidence of a respectable well informed inhabitant who was living there then, and resides there now.

I presume it will not be denied, that those who served during the war in Saint Domingo, where so many British troops perished, must have had some experience of yellow fever; I remained there till the last, and saw the work of destruction completed. At first, every new comer, whether medical or otherwise, had his fears; or I should rather say, had the firmest belief in contagion; but with none, did that prejudice ever remain beyond the year. It vanished infallibly as soon as he saw and had experience of the disease; and I can declare, that during the latter years of our sojourn there, with hundreds of cases daily before our eyes, mixed in every conceivable way with the surgical, the convalescent and the healthy*, I never even heard

* This was often inevitable from the want of hospital accommodation. 
the idea started, nor do I recollect a single precaution, advice, or observation that acknowledged the existence of contagion, ever being directed to the medical staff of the army from any quarter. I appeal to the writings of Dr. M'Lean, the living evidence of Mr. Weir, Doctor Jackson, Doctors Theodore, Gordon, Borland, Inspector Warren, and all the medical officers who served there, to bear me out in this assertion. I appeal to the evidence of every medical officer now serving in the West Indies, that has ever had experience of the disease, (for there may very probably be found contagionists among those who never saw it,) to say whether in their lives they ever met with a case of yellow fever that could with greater feasibility be traced to a personal communication with a subject labouring under the disease, than to the ordinary natural causes from which it has been proved to originate.

Another piece of doctrine has been promulgated from the writings of the authors above alluded tothat the yellow fever cannot be received by the same subject more than once. Of this we again

dation. In the 67 th regiment of which I was surgeon, and which for nearly three years never sent a man away from the regiment to general hospital, I had only one large ward for the whole, without separation or partitions of any kind; and when severe ardent yellow fevers, as they often did, nearly filled the hospital, the punished, the ulcerated, the wounded, and the convalescent, were obliged to retain or take a bed wherever a vacancy occurred. 
who live amongst yellow fevers not only know nothing, but we see it contradicted by the daily experience of our lives. We are aware that as it is particularly a disease of the robust, the sanguineous and the rigid of fibre, he who has escaped from one serious attack is completely disqualified for a second in this climate, until he can find the means of restoring the inflammatory diathesis by a course of the unnaturally high gross living to which Englishmen are so prone; and we do not deny that the susceptibility towards a very acute disease may be greatly lessened by the exhaustion of that principle through the attack of such a one as yellow fever. But all experienced officers here have seen second attacks under those circumstances, and have witnessed two, three, and four in the same person, when cut short by timely remedies and not permitted to run their course; terminating ultimately in black vomit, hæmorrhages and death.

It is certain that if having had the West India yellow fever secures an exemption from the Gibraltar one, this last gives no security in kind. Captain Johnston, of the Queen's regiment now here, had the Gibraltar fever in 1804, and he has just now recovered with difficulty from a very alarming attack of the prevailing epidemic. It is not usual to meet with men who in the course of their lives have sustained two attacks of typhus gravior, and in as far as my experience goes, I am 
satisfied that it would be more easy to find well authenticated instances amongst those -who have visited the West Indies, of repeated attacks of yellow fever than of the other disease. In this small garrison, for instance, a man of the Queen's regiment died lately of aggravated yellow fever, after having since his arrival here suffered a wellmarked attack of the same. Another of the 25th regiment also died in the same way a short time ago, who had been treated by Doctor Jackson for the epidemic fever that prevailed in Saint Kitt's in 1812, where his case was reckoned a remarkable one, on account of its severity, and various others of a similar kind have occurred in that corps.

The black vomit being ordinarily a mortal symptom, cannot of course be often seen twice in the same subject, and I am aware that the subtle disputant will here have a subterfuge, by denying that the first attacks could be yellow fever, the true Bulam fever. But again we have proofs even in the small island of Barbadoes, where the-first patient that Dr. Caddell (a physician of the greatest experience) ever treated, had a distinct black vomit, (it made the strongest impression upon him,) he recovered miraculously, and died some years afterwards of the same disease, and with the same symptom.

A third writer of acknowledged talents has, no doubt unintentionally, done much during a series of 
years to alarm the public mind on the subjeet of contagion. I feel that I have a right to use this language in regard to Dr. Chisholm's assertion, from the following circumstances. In page 119 , Vol. II. of second edition of his work on the fevers of the West-Indies, he states that the General Elliot, East-Indiaman, imported the contagion of yellow fever into Fort Royal, Martinique, in June 1796. This was one of the ships appointed in that spring to take out the scattered remains and detachments of Admiral Christian's armament, that had been so severely handled by the elements the preceding winter. It so happened that $I$, being then on my way to join the 67th regiment in Saint Domingo, was ordered on board of her to take charge of the detachments of the Buffs, 38th and 60th, she was carrying out : I also acted as surgeon to the ship's crew, and can declare that when we landed at Martinique there was not a single sick human being, except the ship's carpenter, who was far gone in consumption; nor had there been the smallest illness amongst us from the day of our sailing at Portsmouth, except a very few of the slightest calentures (I had one) when we first entered the tropics, none of which endured more than twelve hours. She sailed from Portsmouth on the 15th of May, and arrived at Martinique, after touching at Barbadoes for orders on the 19th or 20th of June *.

* Vide Inspection Report on Grenada, April; 1816. 
Having thus committed myself to oppugn the opinions and doctrines of men whose writings may have given them character and estimation in the world, far beyond any thing I can boast of, it seems to be right that I should state what I conceive to be the source of this endemic fever, which I deny to be ever imported and contagious.

The generality of the West-India towns, and consequently of the garrisons for the troops, are situated on the leeward shores of the country, at the bottom of the deepest bays that can be found, as a protection to their trade against the winds from the sea. The soil in such localities must always be alluvial, and is often marshy. Nine-tenths of the towns are inclosed by high hills rising immediately behind them, which exclude the breeze that in its natural course ought to reach them from the windward side of the country; and if we add to this that their elevation is generally little above the level of the sea, we shall have abundant reason for concluding, that if the highest degrees of reflected tropical heat, defective perflation, and the miasmata that reside in marshy soils, or may be formed in the drier alluvial ones by heavy rains, can produce aggravated remittent fever, it must happen under such circumstances, which, so far from being corrected by an enlightened police of towns, are often forced into unnatural activity by the utter disregard of those regulations of cleanliness and order, that 
all well governed communities take pride in observing.

The settlements of the planter in like manner are formed, not on the elevated mountain ridge from which the periodical rains have washed away the soil, but in the alluvial grounds beneath, where his labours can with more certainty be turned to profit. Now is it to be wondered at under such circumstances, that a body of raw troops or young civilians, come to settle in town or country, should be swept away by tropical fevers? The wonder in fact ought to be why it does not happen with more unerring certainty; for there are seasons and even courses of seasons under apparently similar circumstances of heat and moisture, when even the declared swamp, which no one can mistake, is comparatively innoxious to the new comer from Europe, and still more so to the seasoned inhabitant of the country*; this begets in the young adventurer or hardened votary of wealth, a fatal delusion of confidence which, though so often exposed by the melancholy recurrence of fatal fevers, is never cured. They vote themselves secure, and despise precaution because they have escaped for a season. Though the constitution of the stranger in fact is ever charged; but is the power that applies the match which cannot accurately be defined or distinguished.

* Vide Inspection Report of Tobago, dated March, 1816. 
On the occult nature of marsh miasmata, and under what circumstances these become clothed with morbific powers, it would be as presumptuous as it would be idle in me to attempt definition, or to prescribe their laws. No one, I believe, can take it upon him to say with precision where they reside, and in what they consist; but from the reports I have already presented on the subject, I feel warranted in believing that their pestiferous quality does not necessarily depend either upon aqueous or vegetable putrefaction, however frequently it may be found combined with both; and that it never proceeds from open masses of water under any circumstances, but that it is destroyed and corrected whenever water can be brought in that state. By this I only mean to say, that the miasmata are not generated from the body of the lake or pool, but from its drying or half dried margins. The swamp is no more than this margin rolled up under another shape. Water kept in stone tanks, or any where so that it can be preserved in bulk, without being absorbed by the surrounding soil, gives out no morbific miasmata. One of the healthiest quarters in the West Indies, is that of the field-officers on Berkshire-hill, Saint Vincent's, the bed-room of which is placed immediately over a deep stone reservoir of water. A blockhouse in Demarara, reported to be one of the healthiest quarters there, is similarly situated; and it is known to all that the fresh water laid for voL. vilr. 
a ship's crew, however putrid, and however much in contact with their sleeping places, produces nothing like marsh fever amongst them. I contend also that it is very certainly generated from the paucity of water where it has previously abounded, provided that paucity be short of actual dryness; that a high temperature of atmospherical heat is indispensable towards its production, and that in proportion to the intensity of temperature, is the intensity of power in the miasmata produced, varying in its effects on the human frame, from the ordinary ague of Europe, and the fever of the mountains of the West-Indies, to the highest degree of aggravated remittent or yellow fever, which is never found remote from the level of the sea; that it is comparatively innoxious to those who have had the good fortune during healthy seasons to become habituated to its influence; and that it attacks with singular peculiarity of selection the robust, the young, and the healthy, in their first approach to its abode. If these be granted me, I think we may be able to explain from the various compositions of soil, its elevation, aspect, and texture, as affording capacity to retain moisture, why every dry one can be brought during an uncommonly wet season, through the influence of tropical heat, into the state of a marsh that gives out noxious vapours, and a marshy one approaching to dryness through previous draught may be made perfectly healthy from the same abundant rains. 
A comparison between the present state of the islands of Barbadoes and Trinidad, will, I think, exemplify this. Every one who knows both countries must allow that the cleared calcareous soil of Barbadoes is by far the most salubrious of the two, and that Bridgetown, bad as it is, is much more healthily situated than post of Spain; yet Trinidad throughout has been perfectly healthy for several months past, while Barbadoes has been greatly afflicted with the very worst yellow fevers. In both places it has rained abundantly, particularly in Trinidad, where they may be said to have had ten months' rain out of the last twelve. These have preserved its extensive marshes ever fresh and condensed the paludal gases; while they converted the alluvial soil on the shelves of table land at Barbadoes into temporary swamps. At Trinidad it ordinarily rains more than 200 days every year, to which the inhabitants owe their preservation, in a great degree, from the worst marsh fevers. During a very dry season several years ago, they suffered most dreadfully from them.

On a smaller scale, and at one coup d'ail, an example of the same may often be seen in the island of Saint Lucia, where it has commonly been remarked, that when the garrison on the lofty position of Morné Fortuné is healthy during the fine dry weather, the inhabitants of the town of Castrus, at the base of the same hill immediately below, within half cannon shot, are visited by the 
worst fevers and vice versa : the dry weather gives: activity to the miasmata, which the rains dilute, refresh, or condense, at the same time that they are forming pools and temporary swamps on the shoulders of the hill, immediately beneath the barracks, on the summit of Morné Fortuné.

We may likewise in the same way explain why a deep ravine; impervious to the rays of the sun and free current of the winds, that has been a watercourse, or where water has stagnated in the wet season, may still, after its surface appears dried by the summer heat, have retained sufficient underground moistare to give out the most dangerous miasmata below, the more dangerous because the more concentrated, from having never been dispelled by the winds. Why in fine, the liealthy and unhealthy soits may, under such circumstances, change places in regard to health, and localities in the neighbourhood of each, under the same modifications of climate, be very differently affected.

In the attempts that have been made to establish the point of yellow fever being a new disease, and belonging allogether to a different family from that of the intermittent and remittent class, much stress has been laid on its seldom occurring at the same time with ague, and its rarely breaking off on convalescence into that type; but, as has been said before, ague is not a common production, however obvious and abundant its sources may be, 
in the hot lowlands on or near the level of the sea, where alone the yellow fever is found. It is very rare, for instance, to hear of an ague originating in the leeward sea-port town of Basse Terre, Guadaloupe, either amongst the troops there or the inhabitants; but in the barracks on the cool marshy hills above the town, at an elevation of less than 1000 feet, it was a very common disease both amongst the officers and the soldiers, while their comrades of the same corps in the barracks of the town, suffered from the more concentrated forms of remittent fever alone. The same may be said of nearly the whole of the West-India towns. They are all so marshy, that in colderlatitudes they could not possibly escape being infested with agues, but these very seldom originate, and are nearly un. known amongst them. In this way it is common to hear the inhabitants of Barbadoes boast that an ague cannot be found in their island; although they have various marshes, particularly near Bridgetown, and during sickly seasons come in for their share of yellow fever. The reason is plain: there are very few ridges in Barbadoes of sufficient elevation ta belong to the region of ague, even supposing their sides to be marshy, which they never are (they are of the driest calcareous strata). The marshes are all in the lowest levels of land; and when their morbific miasmata act upon the human body, they produce the greater or less concentrated forms of remittent fever, according as their powers are regulated by the temperature and 
climate of the season, or as the subject is presented under more or less favourable circumstances of seasoning, excitement, \&c.*

This subject is not without difficulties, for it is certain that for years together, these supposed fomites of fever are comparatively harmless; and that at other times new comers suffer the worst attacks in places where it is difficult even to imagine the existence of any thing like marsh miasmata. Hence it has been usual in the West-Indies to believe that there are two forms of yellow fever. originating from different causes, the one from the marsh poison, the other from pure excitement in the stranger, both so perfectly alike that the most experienced cannot distinguish any difference; but this surely is not more strange than that fevers, ex. actly the same as marsh fevers, should originate in the driest ravines of hot countries, and that the effects of the Mediterranean, and I may add the Peninsular Malaria, are experienced in the most arid, often even elevated scites, where the existence of miasmata is certainly less demonstrable than in nine-tenths of the West-India localities.

I am far from presuming to deny (though I believe the contrary, for the reasons given in my an. swer to the queries upon the Regalia,) that there may be such a fever as that from pure excitement;

* Vide Note at the End. 
for soldiers and others have been attacked and died of yellow fever before they landed in the WestIndies, or could be exposed to the influence of land miasmata in any shape. From this it would appear that a calenture, the synocha of Cullen, (the pure offspring of heat, as pneumonia is of cold) runs a course similar to the yeliow fever, and to use the language of the humoral pathologist, that the blood is broken down and dissolved by its action, the vessels of the stomach, and under the skin, giving way in a remarkable manner, the same as in what has been called the true Bulam. The inference to be deduced in that case, must be that all violent tropical fevers have a tendency to run into this corruption of the fluids, or morbid incontractility of vessels, as much as the synochous fevers in the hospitals of England are prone to assume the typhous types when long protracted.

To the argument that the highest degree of concentrated remittent or yellow fever, should neither remit nor break off into ague, it seems sufficient to reply, that for any disease to observe regular laws, it is necessary that the vital organs principally affected should continue in a certain degree of integrity; that their functions should only be perverted and disturbed to a given point; that they should still be discernible as functions, and not be utterly overwhelmed and extinguished by the violent cerebral action and speedy disorganization of the stomach that takes place in aggravated yellow fever. As 
the ulcer of a specific poison that would run a re. gulated course according to acknowledged laws, if it be driven to a high inflammation or sphacelus, no longer belongs to the original stock, and is emancipated from those laws; so the violent actions of the above fever impair and destroy the animal functions by which its crisis and remissions are regulated, or speedily engender a new disease; as new as the conversion of an ordinary venereal chancre into a phagedenic slough, through the application of a potential cautery.

I feel that this almost inscrutable subject is at present greatly beyond my depth: I wish only to shew that the difficulties of reconciling the phenomena of remittent with what has been called yellow fever, are not so great as what has been represented, nor greater than what exist in many other diseases, respecting the identity and origin of which the same difficulties have not been started. The difference between the different degrees of the intertropical fever, that are characterised by irritability of stomach, and terminate occasionally in discolorations of the skin, or what have been called remittent, bilious remittent, and Bulam, are surely not greater than what we see daily in another disease at home, which, however, is propagated by different laws. There scarlatina will attack one pa: tient in a form so mild, that but for the subsequent desquamation of the cuticle, it would be difficult to detect its existence. Another will have vivid erup: 
tions and high phlogistic symptoms, while a third exhibits a low putrid malignant plague, with gangrenous sore throat, and scarcely any eruptions at all. No one thinks of doubting the identity of the disease in these three conditions, because they have all one common property, the capability of communicating the infection to others; but this last is not an essential quality of many other acute distempers, nor is it more characteristic than that of the Bulam fever being limited almost exclusively to the unseasoned and the stranger. It is surely more probable that the endemic causes of disease should operate upon their unseasoned bodies with peculiar severity, so as to produce something more than an ordinary remittent fever, than that they should remain altogether exempted from their operation, and even while the Creoles and the season. ed are suffering their limited share of endemic ills, be amenable solely to a peculiar contagion reserved altogether for their use, or imported with incomprehensible punctuality for the occasion of armaments newly arrived, sultry calms and long continued droughts, by which the exhalations from the earth. are known to be sublimed into peculiar activity.

It is fortunate that amidst the labyrinth of conjecture in which the medical inquirer finds himself bewildered, there are nevertheless some points in regard to this fever, where he will find a firm 
footing from which he is not to be taken down. These I would arrange in the following order.

1st. That the yellow fever never begins, and cannot continue to exist in a temperature of heat lower than the ordinary temperature of the tropics, on the level of the sea; which temperature is not the ordinary one of agues, however moist the soil may be, but of remittents and the higher degrees of ardent fever.

2nd. That even within the tropics, it is confined in all the islands to the sea-coast; and can only spread into the interior of continents where the country is flat and low, possessing little elevation above that level, and retaining the above temperature.

3rd. That it uniformly is more apt to arise and to spread where miasmata, or what would constitute the elements of intermittent or remittent fevers in colder countries, openly abound.

4th. That a comparatively high degree of bodily vigour and rigidity of fibre, such as the young sanguineous newly arrived European ordinarily brings with him to the West-Indies, is for the most part essential to the developement of the disease.

5th, That Europeans suffer in point of priority 
and severity of attack, precisely in the degree that they possess the foresaid vigour of constitution, and that when relaxed by long residence or other causes, they become like the Creoles and people of colour, in a great degree exempt from its influence.

The above positions I believe to be indisputable by any controversialist. They are proved by the evidence of many authors, and can be made evident to every observer. The more difficult points to estab lish (because not admitting of the same proofs) are that occult miasmata, to the amount that constitutes malaria, if I may use that expression, exist in most of the low leeward alluvial situations where strangers always first arrive at, and commonly reside.

By malaria as never belonging to open marshes, I mean to express something that is more decidedly than miasmata the product of underground moisture, which can only be sublimed, so as to produce its specific effects, by long continued solar heat; a more subtile miasma in fact, of which the surface gives no warning, but of which the existence is proved from its effects on habitations that are placed in the drought of the dry ditches of forts, no matter how rocky or dry, if they are deep and of deep ravines. At Fort Matilda, in Basseterre, Guadaloupe, a well raised artillery store-house and guard-room placed in a bouchure, at the confluence 
of two of the ditches, was found to be utterly uninhabitable. The best seasoned of our old artillery-men were sure to be seized with fever if they slept there a single night; there was a spring of pure water out of the rock in one of the ditches, the course of which was kept clear, but that made no difference in point of health. The same malign influence was observed to affect houses that were placed opposite the deep ravines of rivers, no matter how pure and pebbly the channel, as also all dwellings situated on the leeward base of the mountains.

Another point of enquiry is, whether these effluvia during certain states of stagnation of atmosphere, such as during the sultry calms of the hurricane months in the West-Indies, accumulate in the dirty ill ventilated streets of West-India towns, to the particular danger of all who are unseasoned to their influence; and whether the constitution of newly arrived strangers from colder countries, when attacked by fever in these situations, is prone to run into, or I should rather say, incapable of assuming any forms but those of the highest degree of ardent fever, from the circumstances laid down in the foregoing position, No. 4.

Why these miasmata should lie dormant for years, and then as if they had been accumulating their forces all the while, burst forth with pestilential epir demic current, as they sometimes do, even to the 
destruction of the best seasoned, I cannot pretend to explain. I believe, however, that the healthiness of seasons in unhealthy climates will be found to depend less on the amount of actual heat and moisture, which has been so often observed and recorded with accuracy by scientific men, than on the ventilation of the climates by powerful regular winds, like the trade-wind between the tropics*; that towns and districts of country will be found cateris paribus to be healthy or otherwise in proportion as they enjoy more or less of this purifying influence; and that whenever it has been withheld for a time, the accumulated morbific emanations from underground moisture will act upon the human body like the accumulated typhoid principle in crowded hospitals, when undiluted with a due proportion of atmospheric air.

I think it must be evident that in these climates we are often on the brink of pestilence ( $I$ use the words pestilence and pestilential throughout this paper merely to signify epidemic) without being aware of our danger, and ignorant consequently of the means by which our escape has been effected. The presence or absence of rain, the continuance of calms, or accession of a particular wind at a particular time; the accumulation of people in towns, and the arrival amongst them of strangers at

* For the last four months there has nearly been an extinction of this wind at Barbadoes. 
particular seasons to furnish moral food for panic, and embody that principle so as to unnerve the whole community, and, when endemic disease breaks out, to give epidemic current: all these, in my opinion, act powerfully to influence the rise and progress of endemic fevers; and they will affect different places as variously as the variety of their soils and the position and form of the country. Thus even to our imperfect knowledge the epidemic visitation this season of yellow fever at Guadaloupe, Barbadoes, and Antigua, while it has spared the equally or more unhealthy countries of Trinidad, Tobago, and Saint Lucia, and when imported into Saint Vincent's would not remain there, may appear less capricious and unaccountable. It would have done the same to the writers on the fever of Spain, if they had not dismissed all their doubts, and set inquiry to rest by attributing the whole to imported contagion. But had they inquired, instead of peremptorily deciding, they might have found that during the epidemic visitation of these fevers, not only do towns and districts escape altogether, as we see at present in the West-Indies, but that different parts of the same town are differently affected: and so limited often is their influence, that one story of a house and one section of a ship will be strongly affected by it, while all other parts of the same tenements remain healthy, and then their wonder at what has been called the desultory progress of this fever during the short course of an European autumn, need not have beep 
so great as to have been inexplicable through any source but that to which they referred it. At Barbadoes our hospitals of late have been in a regular course'of importation of the yellow fever from the navy, but not even inoculation has been able to produce the disease upon any member of the hospital corps, by whom I may truly say that the sick have received with open arms; for the antisocial doctrines of ideal contagions are not preached amongst us here, to the prejudice of duty and humanity.

Hospital assistant Moon, on opening the body of a patient that had died of very aggravated yellow fever, wounded his finger. The wound produced high inflammation, similar to what occurs in the dissection rooms of England, running up the course of the lymphatics to the glands of the axilla, with symptomatic fever, but no more.

An example of the efficacy of quarantine laws where no contagion exists, may here be amusing. At Martinique they established a strict quarantine, particularly directed against Guadaloupe, and they have been consumed with yellow fevers; but at Dominique, Tobago, Saint Vincent's, \&c. where they established none at all, they have not had, in as far as I have learnt, a single case, although at the last-mentioned island both the Tigris and Childers ships of war imported distinct well-marked instances of the disease from Point au Pitre, on the 
evacuation of Guadaloupe. The first of the above ships continued healthy for nearly three months afterwards; the second has been the subject of a particular report.

It is now several years since the highest degree of remittent or yellow fever has prevailed epidemically in the West-Indies. Sporadic cases have been constantly occurring, but this season it has visited in a remarkable manner some of the un. healthiest of the towns, such as Point au Pitre and Basseterre, Saint John's, Antigua, and Bridgetown, Barbadoes. In all it has been confined for the most part to the towns, and, except at Bridgetown, to unseasoned Europeans. There it extended to unseasoned sojourners, even Creoles from the interior of the country, who in the time of the insurrection were obliged to resort to the town on military duty. The French strangers from Europe suffered more severely in Guadaloupe than I had ever known any importation of similar numbers do in the British colonies. In no one instance was an attack of true yellow fever seen amongst the British troops there; but if any one doubted of their suffering from the same exciting causes of fever, though modified from the circumstances of seasoning, he might in the course of half an hour's ride any morning have satisfied himself of the identity of the three diseases, in the persons of the stranger expiring in his lodgings with black vomit and hæmorrhages (Vide Appendix, No. 8.); the 
seasoned soldier at the hospital close by, probably doing the same, under the regular type of remittent fever, with a retentive stomach and comatose brain ; or the same description of subject, or planter of the country, undergoing the regular paroxysm of ague in the cooler quarters of Valtier or Beau Soleil Barracks, on the higher grounds immediately above the town.

At Barbadoes the distinction and identity has been still more nicely marked. There a perfectly raw newly arrived regiment (the Queen's) came out from England in May, and were quartered in Saint Ann's Barracks, on a comparatively elevated table of well ventilated rocky land, at a time that numerous civilian strangers were arriving at the hot unwholesome town within the distance of a mile, and the communication between the barracks and the town had not been restrained by any regulation. These last have been cut off in a great proportion by the very worst symptoms of yellow fever; but though the Queen's have lost many men from severe well marked remittent fevers, only eight * of those amongst the equally unseasoned military arrived at the highest degree of yellow fever, as characterized by black vomitings and hæmorrhages. Their fatal fevers have often approached very near to it; the remittent form

* Several more have occurred since this paper was written.

VOL. VIII.

$\mathbf{L}$ 
losing type as it always does, when aggravated so as to become ardent and continued, with constant vomitings; but except in the eight cases just men, tioned, none of them shewed the diagnostic symptoms of the very highest degree, which were almost invariably present upon those that died in the town.

The 25th and 60th regiments have in like manne had numerous cases that died with a yellow or fuscous livid skin after frequent vomitings, that were sometimes ropy and brownish, but never black. The colour of the matter vomited is not essential to constitute the diagnosis of this form of fever; but the increase of the fluid ejected beyond what has been taken in, more particularly if glairy, certainly is, and decidedly marks the gastric affection.

Here within a very short space we see a minute modification of cause operating as minute a difference in the form of the fever;-a precise one, however, from which the inference is unquestionable, that the troops and their neighbours the Civilians were not on the same niche, but certainly within the same pale of morbific influences.

The difference of heat between the barracks and the streets of the town, as marked by the thermometer, has been seldom less than four, and 
often as much as six degrees, during all the hot sultry days of the present season. How long they are to preserve that station of health is doubtful, for there are marshes in abundance immediately to leeward of Saint Ann's, which, in close sultry seasons like the present, have produced amongst the newly arrived military, the very worst degrees of ardent tropical fever. And here, as marking the nicer shades of malarious influence, and the total absence of contagion, it may not be uninstructive to remark, that though the Queen's inhabited a large barrack in common with part of the well seasoned 25th and 60th regiments, they alone experienced any difference of health between those that inhabited the ground-floors and the upper story*; that no infection spread from their cases of black vomit among themselves, or to their comrades of the other regiments in the same barrack; that they have lost no hospital servants from fever, and had scarcely any sick + ; that all the white servants in the hospitals at Barbadoes; though engaged in attending many of the worst cases of yellow fever that ever were seen as landed from the navy, have been healthier beyond all com:

* Vide Appendix, No. 10.

† They have employed too their full share of hospital servants? their sick, though victualled in the general hospital for want of a regimental one, being arranged there regimentally, and atteded by their own medical officers and servants, under the direction of the physician. 
pare, and suffered less from fever in proportion to their numbers, than any other class of military in garrison*; and that no case of fever has occurred in the person of any medical officer, except one, who, for five weeks previously, had been stationed at a healthy military port in the country, remote from the theatre of fevers and from all the hospitals.

This remarkable exemption of the hospital servants, certainly goes to prove what has so often been observed here, that when the body is charged with the elements of fever, (whatever these may be,) its immediate exciting causes are exposure to the heat of the sun, more especially when fatigued with exercise, getting wet, and drunkenness; to all of which the hospital orderlies were much less exposed than the troops in barracks. Of our medical staff, the physician and five of the assistants are of the class of the newly arrived, and amongst the rest, few have had the benefit of the preservative (a previous attack) mentioned by Mr. Pym. The hospital assistant that died was stationed in one of the healthiest posts of the West Indies, where, with the exception of one woman, there has not been a single case of fever reported during the whole season. His death was accounted for in the statement I transmitted of his case.

I have dilated upon these facts because it is only

* Vide Appendix, No. 11. 
from observations upon masses of men, and comparisons made under different circumstances, that wellfounded conclusions can be drawn in respect to the causes and properties of disease. 'Thus whoever has seen the greater portion of an army affected with dysentery or a particular kind of fever, with hundreds of cases and facts constantly before his eyes, can scarcely fail to know whether these diseases are contagious or not. The physician in civil life, however superior he may be in learning and talents, as he sees only insulated cases, cannot have the same advantages, and must be much more liable to form erroneous conclusions. He may see, for instance, during the autumnal season of Europe, the inhabitants of a humid unwholesome house fall ill with dysentery one after the other, according to the degree of predisposition or stamina of resistance in the respective individuals, and thence conclude with much apparent justice, that dysentery is a contagious disease; but take him to the well regulated encampment, and shew him in its hospitals, what every experienced medical officer has seen, a thousand dysenteric patients attended by a hundred servants, without affecting one of the attendants, he certainly would for ever be cured of the delusion. In like manner, when he comes to practise in a West-India town, he may find a yellow fever in an endemial house, (if I may use the expression,) which, in conformity to the above rule, attacks in succession all its inhabitants, and from thence make his proclamation of contagion to the af. 
frighted people ; but if he stepped to the neighbouring military hospital, and saw the same description of patients mixed in every conceivable variety with the convalescent, the surgical and the healthy, yet affecting no one, he would never after that, whatever he might say, believe it to be a contagious disease.

A remarkable instance of this lately occurred here, in the practice of Dr. Caddell. Two Creole ladies inhabited an insulated house, in the low suburbs of Bridgetown. It was ascertained that partly through indolence or fear, neither of them had gone out beyond their own premises for ten weeks previously, yet at the end of that time, and without any discoverable or even supposable communication with the sick in the town, both took the yellow fever, and one of them died of the black vomit.

Unfortunately these opportunities of observation are not always sought for; and as experience of yellow fever in civil life, is often trifling, limited to particular seasons and circumstances of exposure in the subject, he may, through defect of experience, believe in his doctrines of contagion to the end, and do his utmost to alarm the public; but the military medical officer, who has once seen the disease in the gross, as it affects newly arrived troops here, never can be deceived in respect to its non-contagious character, (if his mind be capable 
of distinguishing truth from error, ) and in fact never is in these climates.

Another reason why, for a course of years, there has been little yellow fever in the West-Indies, may also be, because the pabulum of the disease has not been supplied from the colder regions in the wonted quantities. The last importation of troops in regiments previous to the arrival of the Queen's being upwards of seven years ago, with the exception of two regiments, the 4th battalion of the 60th, composed of foreigners, and the York Chasseurs, composed of deserters of all descriptions, and the crowds of civilians that used to shoal out and perish here, having found employment through the circumstances of the war elsewhere. All the regiments however now here, so long underwent the ordeal of seasoning in no long time after their arrival, and buried a large portion of their youngest soldiers. The recruits that successively came out to them fared better; for instead of finding themselves in a community at their first arrival, where all was inexperience and panic, they became at once members of a healthy seasoned body, and were taught by experienced officers as well as by the experience of their comrades, how to take care of themselves. In this way confidence was inspired, and they suffered but little; but if new regiments are to be sent out in corps, and the current of emigration is again to be directed towards the colonies, it will soon be seen that the yellow fever was only weak. 
ened from want of its proper food, and that it will again prevail for as long as that food is supplied.

I trust that in the foregoing, and in the Appendix subjoined, it will be seen that $I$ have adduced some facts, and supported them by reasonings, to shew that the remittent, the bilious remittent, and the Bulam, belong to the same family, and are only different degrees of intertropical fever; that they, no more than other severe fevers, exempt the patient from suffering subsequent attacks ; that under ordinary circumstances of ventilation, they are not contagious; that their origin is always endemic; and that therefore the idea of their ever being propagated from imported contagion is chimerical.

Under the contrary circumstances $I$ have no doubt but that a typhoid infection may exist here the same as elsewhere, which, however, is certainly dissipated, as soon as ventilation and purity are restored. This was exemplified in the Childers brig that lately arrived at Barbadoes, in so distressing a state from Trinidad. The fevers on board of her from crowding below decks when at sea, ceased to be yellow ones, and became as truly typhoid as any I ever saw; but all that were taken ill after she came into harbour, and promptly removed to our excellent hospital, retained the character of yellow fevers in every respect, and shewed not the least of the typhoid type. That the ship was impregnated with a typhoid contagion, capable 
of infecting others within its sphere, I have as little doubt; and am sure from what I have seen, that crowded hospitals on shore may be brought for a time to the same dangerous condition from undue accumulation of sick, even in these climates. Some well marked cases of typhous fever, and others of a mixed nature, have lately been sent to the hospital, from the huts in the rear of the barrack of the Queen's regiment, into which the married people of that corps crowded in great numbers, and they had become in consequence dirty and ill ventilated to a very great degree. Some of these huts, containing more than one family, where washing and every species of nuisance and disorder was to be found, did not contain more than ten feet by eight within their walls, which were of the thinnest shingles, and afforded little or no protection against the sun's heat.

I cannot pretend altogether to say, that I have proved these points ; for how few amongst the everchanging phænomena of diseases, admit of being subjected to the rules of evidence! and I am aware of how much I have been favoured by circumstances, and of what a different interpretation the facts I have collected would have borne, had the present epidemic that now afflicts the islands broke out in the ordinary course of the seasons a year earlier, at the time the Regalia was here; for these, instead of assisting me to elicit the truth in the manner they have done, would in that case have been turned to 
the confirmation of error, and the perpetuation of the delusion in regard to imported contagions.

Signed,

W. Fergusson,

Inspector of Hospitals.

NOTE.

Barbadoes, with the exception of Bridgetown, is the healthiest of the islands, because it is the best cleared, and has no mountain lines to obstruct the sea breeze. The soil is calcareous, disposed for the most part throughout a successive series of ridges on shelves or tables of land without rivers or watercourses to carry off moisture; but the trade wind makes a constant breach over it, to use a nautical expression, night and day ; and though it has marshes, they are so uniformly swept by the current of air, that a stranger is stared at when he inquires if they are not unwholesome. In fact they rarely prove injurious to the health of the seasoned settlers, though they are highly capable of being so in close sultry weather, like that of the present most unnatural season; but to tell them so either in Barbadoes or elsewhere, would only be a waste of words. Whoever has escaped for a season, can never afterwards be máde to believe that the marsh is unwholesome either to himself or to others, and when overtaken by endemic fevers, he lays the blame on the sun, the moon, atmospherical vicissitudes, errors in diet, or infection, \&c. Even the medical men, who 
ought to know better, are often thrown off their guard by this delusion of experience, and from living themselves in unwholesome localities, give countenance to the errors of the people. No one, after he has once committed himself to a choice of residence, likes to be told that from want of knowledge he has acted without due precaution, and he cherishes and defends the error, like the virtuous prejudices of national partiality, even though he himself should fall a victim. In this way the attempt to convince will generally be vain. The inhabitants will continue to live where they have lived before, often escaping themselves, but still more frequently deluding the unseasoned to their destruction. Bridgetown has abundancè of marshes even to windward, yet no one ever thinks of draining them, and when the stranger is startled at their appearance, the inhabitants point to their old men and bid him dispel his fears. Two Generals'* families perished bodily within the last 12 years, at the Government House on the outskirts of the town; yet for all that time and for how much longer I cannot tell, there was till very lately a foul open piece of swamp behind one part of the premises, which could have been thoroughly drained at any time by sinking for a few yards a drain of two feet in depth.

* Sir William Myers and General Grenfield. 


\section{APPENDIX I.}

Extract of Inspection Report to the Commander of the Forces, on the State of the Regalia Transport on the 26th of September, 1815, then appointed to carry home Invalids to England.

1. That the crew on the coast of Africa was healthy till the blacks were sent on board.

2. That about the same time that the blacks embarked, a quantity of green wood was laid in for fuel.

3. That soon after the fever broke out, and several were taken ill, and two died the first day after sailing.

4. That the crew continued to fall ill one after another on the passage, until all except one boy had suffered attacks of fever, and five out of twenty-one had died before arriving at Barbadoes.

5. That the captain's wife sickened and died after making the harbour where the ship remained four days, and that the captain immediately after sickened and died, on the passage to the Saints.

6. That the ship remained two days at the Saints, after which she sailed for Antigua, where she remained three days before returning to Bar- 
badoes, during which time a mate that had been shipped at Barbadoes, from another of the African ships reported to be healthy, sickened and died. Also a boy that had been taken at Barbadoes from the Lord Eldon, then a perfectly healthy transport, fell ill and was sent to the hospital; and the apprentice to the ship, the only individual that had hitherto escaped, for the first time took the fever.

7. That on her return to Barbadoes she shipped a new mate from a healthy Newfoundland ship, who on the ninth morning of his being on board, was found by me in a state of fever, and sent to the hospital.

8. That during the passage from Sierra Leone, and the short voyages through the islands, she has been under a constant course of fumigations by fires and otherwise; that she has now been fresh painted, and is at present, and according to every evidence that could be collected, has been in as clean a state as possible.

9. That all who died were affected with vomitings and bleedings from the mouth, nose, and other places.

\section{Addenda.}

10. That the Regalia shipped three fresh men about the time the crew commenced the work of clearing her hold, one of whom took the fever and 
was sent to the hospital in Barbadoes, and another died at Guadaloupe of the yellow fever on her passage home.

11. That no yellow fever existed at that time in Bridgetown, amongst the ships in the bay, or the troops in garrison; the first case of yellow fever that was heard of in the town, occurred about the beginning of the succeeding year, in the person of a youth, a stranger from Europe, belonging to one of the mercantile houses, and that for more than twelve months after the arrival of the Regalia, none

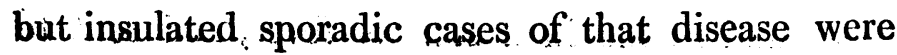
known in Barbadoes.

\section{APPENDIX II.}

Extract of a Communication to the Commissioners for. Transports, on the supposed Infectious Property of Yellow Fever so called, by Mr. MortiMER, Principal Naval Medical Officer at Barbadoes.

"We do not allow the fever of the West Indies, commonly called ' yellow fever,' to be at all infectious in any of its forms or stages.

6. We have never known of an instance of its communication to patients at the several naval hospitals, whilst under cure for other complaints, 
though such patients have never been interdicted, on the contrary, encouraged to offer every addi. tional aid, for the greater comfort of their suffering brethren.

"We are of opinion, in contradiction to that stated to be Dr. Bancroft's, that vapours emitted from holds of ships, having in them the commixture of various animal and vegetable substances, in a state of putrefaction, are quite sufficient for the production of the worst kind of Bulam fevers $i$ that to such effluvia may be justly attributed much of the depopulation occurring amongst Europeans in intertropical climates.

"We are borne out in this opinion from the numerous examples happening in our own practice, a few of which have been related, and of others made known to us by men of indefatigable research, and of unquestioned veracity.

"6 We have shewn in the history of the Regalia Transport, that she continued perfectly healthy during the several weeks she was employed on the African coast, and until she shipped a quantity of green wood, cut down and brought on board the same day.. We have it in proof that fever made its appearance soon afterwards; that it prevailed with unabated malignity on her arrival at Barbadoes, where it was asserted she had imported in 
the persons of black recruits a highly pestilential disease.

co We have it furthermore in evidence, that whilst at English harbour she underwent fumigation as ordered by Commissioner Lewis, without the least effect in arresting future attacks, or their fatality; and that it was not until after her arrival in Carlisle Bay, where she was completely cleared, and with her hatchways closed, her whole hold exposed to the concentrated heat of many stoves, that fever ceased.

“ That the causes existed in the vessel, and that they were of most malignant kind, are evidenced by their speedy effects on every man engaged to renew the place of the one dead; and if to the most incredulous further proof were deemed necessary, it might be adduced in its fatal operation on the cook of the ship (a man who died here), a man upwards of fifty years old, and the only one of the original ship's crew, who had, up to the period of the cleaning of the hold, been exempted from seizure.

"I have particularized this ship, because she is not only the most recent instance of the decided effects of the noxious effluvia on the human constitution; but because, to the authority and weight of representation from Dr. Fergusson, Inspector of 
army hospitals, may be attributed the prompt clearance of the vessel, and I fully believe, therefore, the safety of many lives."

Signed,

John Mortimer.

\section{APPENDIX III.}

Report of Deputy Inspector Forbes, on a Case of Fever belonging to the Regalia Transport, that terminated fatally in the Navy Hospital at Barbadoes.

" James Champion. Case of fever which terminated fatally.

" On Sunday he was seized with long and continued rigors, succeeded by a short period of heat, pain in the eyes, loins and lower extremities; belly costive; these symptoms subsided altogether, and he remained well till the next day at three o'clock, when a similar attack recurred, and he was received at the Naval Hospital at noon this day. The belly continuing bound, purgatives were administered with such relief, that in the evening he again considered himself well. The following day his eyes became of a dark red; he complained of a deepseated pain in his head, and accompanied by great increase of heat; blood was then drawn from the vol. viII. 
arm and temporal artery; large doses of calomel were administered, also friction with mercurial ointment; a blister was applied to the head, and sinapisms to the feet. These symptoms continued until Wednesday, when they became accompanied with constant vomiting, the fluid exhibited a coffee colour, and latterly much affected with spasm.

“ He died this day at two o'clock, P.M.

\section{Dissection.}

"The head and stomach exhibited great marks of inflammation; the vessels of the meninges were loaded with blood; the surface of the brain, especially in the course of the longitudinal sinus, very turgid; the outer coat of the stomach as though rubbed off by a blow, and the inside surface in several parts of a mottled appearance, and contained about half a pint of fluid of a dirty brown hue; the gall-bladder was distended with fluid of the same appearance; the liver was spotted in various parts; the other part of the viscera did not exhibit any marks of disease. The body was not in the least discoloured after death.

"This man had been ill for some days previous to his being sent to the hospital, and by the man's own account, seems, to have been "brought on by 
slèeping on deck, and getting thoroughly wet, and remaining in that state without changing."

Signed,

P. Forbes,

Deputy Inspector.

\section{APPENDIX IV.}

Report of Acting Staff Surgeon Ayton on a Case of Fever that terminated fatally, on Board the Regalia Transport, Basseterre Roads; Guadaloupe.

Vaulters, Guadaloupe, February 27th, 1816.

SIR,

"In compliance with your request, I beg leave to state to you, that I visited the transport ship Regalia, on her arrival here from Barbadoes, I believe early in the month of last November. I inspected the ship's crew, and found them perfectly healthy with the exception of one man, who I was told had been ill three or four days: he was a stout young man, of a full habit: he complained of pain in the fore part of his head, with sickness of stomach; the eyes were suffused, the tongue loaded, and there was a dingy yellowness about the neck: the pulse was a little quickened, but not irregular or hard, and the skin moist with no very great degree of heat. I could not exactly ascertain what 
medicine he had taken, but I directed the following to be given him immediately;

R Hydr. Submur. gr. x.

Pulv. Jalap. 3j M. ft. pulv.

this was about three o'clock in the afternoon; the next morning, as I was proceeding to the beach to go on board, I met the captain of her, who informed me the man had just before died, having previously vomited a quantity of black matter."

Signed,

$$
\text { R. Axton, }
$$

Acting Staff Surgeon to the Forces.

To Dr. Fergusson,

Inspector of Hospitals, \&c. \&c.

\section{APPENDIX, V.}

Extract of Inspection Report on the Island of Martinique, by Doctor Menzies, Deputy Inspector of Hospitals.

$\therefore$.6. The Bomb-Proofs are excavations made in the rock below all the works, and near the level of the sea. On the right of the road, betwixt the first and third of these, the rock is of soft sandstone; the entrances are on a level with the road, and the square openings intended as windows somewhat higher. The height of the apartments is eight or nine feet, the breadth about twelve; they are neither paved nor floored, and there are no ham- 
mock rails, nor the appearance of there ever having been any: indeed they have seldom been occupied except during a siege. In rainy weather there is an oozing of water from the roof and sides anteriorly, which renders them damp. Some part of the rock above these Bomb-Proofs, has the appearance of a concretion of sand and small stones. There are, at one end, interior rooms with arched passages leading to them, and air-holes cut perpendicularly for the admission of light, and which may create some ventilation.

"The principal remarks that seem to offer regarding the salubrity of these as a quarter for troops, are the uncommon lowness of them, there being a barrier gate at each end; a wall of fifteen feet directly to windward of them, and no thoroughfare, nor means of creating a draught of air, except the partial air-holes alluded to, as well as the necessary dampness, both from the nature of the rock, and from the non-admission of air to purify, and to correct humidity after rains; and these independent of the general situation of Fort Edward, in regard to the surrounding country."

Signed,

Alexander Menzies, Deputy Inspector of Hospitals. 


\section{APPENDIX VI.}

Extract from the same Report.

"In the third of these ravines, but by much the most considerable, is the village of Case Pilote, built on the beach. There is a church and endowment for a clergyman; the soil seems good, and the sugar-cane grows on a small scale. There are two streams that run into the sea upon each flank of the village, and the wind observes the same course as at Case Navierre. The extreme breadth of the ravine did not appear to me to exceed three-fourths of a mile in the broadest part, and not more than one-fourth at the village; and the apparent extent towards the mountains, not more than a mile, at least, before the view terminates. I have not learnt that to the natives this place is unhealthy; what it might prove to new comers I have some doubt; from analogy drawn from other places similarly situated, I should not consider it as healthy. One of these streams takes a sweep and terminates in a serpentine pool of almost stagnant water, close upon the village. The ground adjacent, to no great extent however, is low and swampy. The principal remarks thatoccur respecting the salubrity of this place, are its being confined in its extent, surrounded with uncultivated grounds, having a partial swamp, not inconsiderable in comparison to the limits of the place; and its being exposed to the oblique rays of the descending sun, on the shore at 
the foot of the immense steep mountains, and those bearing north-east almost directly to windward."

Signed,

$$
\text { Alexander Menzies, }
$$

Deputy Inspector of Hospitals.

\section{APPENDIX VII.}

Deputy Inspector Forbes's Statement of Admissions, Deaths, and Discharges, of the unattached African Recruits.

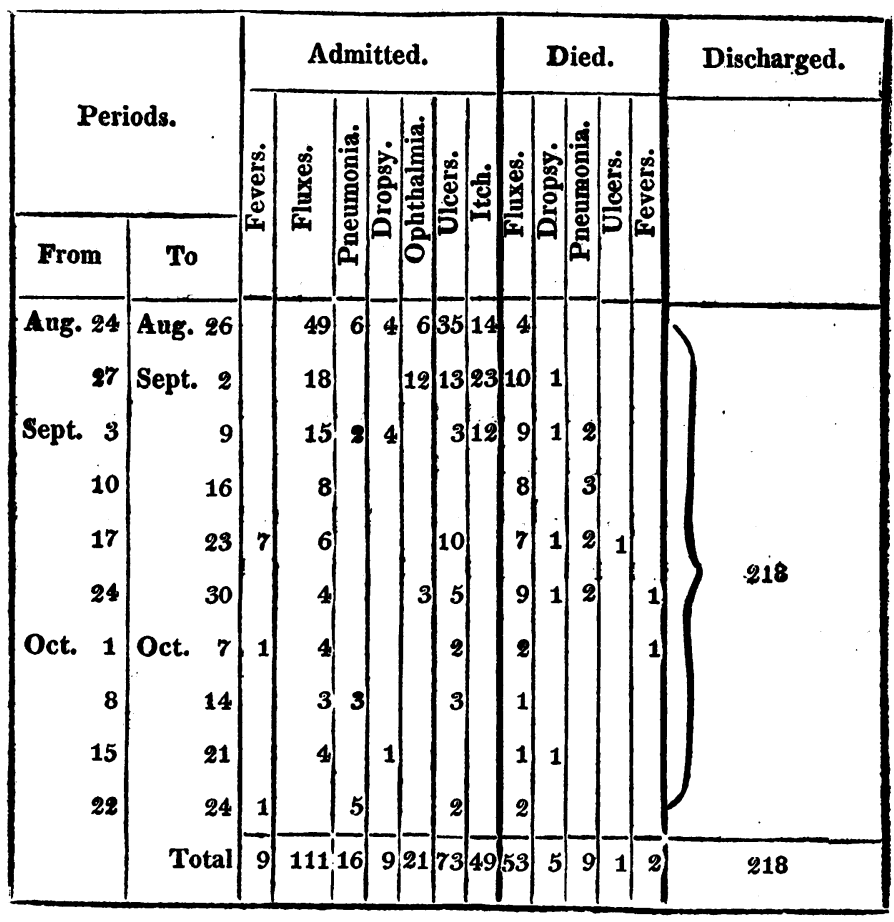




\section{APPENDIX VIII.}

\section{List of Persons who have lately died in Basse Terre, Guadaloupe, May 1st to May 31st.}

\begin{tabular}{|c|c|c|c|c|c|}
\hline Names. & Age. & Disease. & $\begin{array}{l}\text { Period } \\
\text { in the } \\
\text { Island. }\end{array}$ & Period ill. & $\begin{array}{l}\text { Leading } \\
\text { Symptoms } \\
\text { of Disease. }\end{array}$ \\
\hline $\begin{array}{r}\text { MMr. Didier. } \\
\text { Huges. } \\
\text { Madue. Denault. } \\
\text { MMm. Berville. } \\
\text { Emar. } \\
\text { Bernard. } \\
\text { Blanchet. } \\
\text { Goudrie. } \\
\text { Sandre. } \\
\text { Madlle. Guenet. }\end{array}$ & $\begin{array}{l}23 \text { ans. } \\
25 \text { ans. } \\
11 \text { ans. } \\
30 \text { ans. } \\
35 \text { ans. } \\
20 \text { ans. } \\
30 \text { ans. } \\
24 \text { ans. } \\
10 \text { ans. }\end{array}$ & 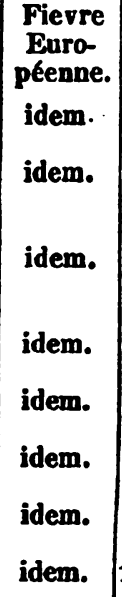 & $\begin{array}{l}4 \text { mois. } \\
4 \text { idem. } \\
\text { Créole. } \\
4 \text { mois. } \\
4 \text { idem. } \\
4 \text { idem. } \\
2 \text { mois. } \\
2 \text { mois. } \\
11 \text { idem. }\end{array}$ & $\begin{array}{l}5 \text { jours mort. } \\
6 \text { idem mort. } \\
6 \text { jours mort. } \\
7 \text { idem idem. } \\
6 \frac{1}{2} \text { jours mort. } \\
7 \text { jours mort. } \\
7 \text { jours mort. } \\
2 \text { jours mort. } \\
4 \text { jours mort. }\end{array}$ & $\begin{array}{l}\text { Vomisse- } \\
\text { ment noir, } \\
\text { hémor- } \\
\text { rhagie na- } \\
\text { zale et } \\
\text { alvine. } \\
\text { Vomisse- } \\
\text { ment noir, } \\
\text { hémor- } \\
\text { rhagie na- } \\
\text { zale. } \\
\text { idem et } \\
\text { idem. } \\
\text { idem. }\end{array}$ \\
\hline
\end{tabular}

Mr. Loriol died in June at the three Rivers; he was just arrived from Europe. Three days illness; black vomiting. One Provençal dead three days ago of the same illness. Seventeen days illness. 12 June.

Signed, "Cereros." 


\section{APPENDIX IX.}

List of Persons who have died in July, 1816, Basse Terre, Guadaloupe.

\begin{tabular}{|c|c|c|c|c|c|}
\hline Names. & Age. & Disease. & $\begin{array}{l}\text { Period } \\
\text { in the } \\
\text { Island. }\end{array}$ & Period ill. & $\begin{array}{c}\text { Leading } \\
\text { Symptoms } \\
\text { of Disease. }\end{array}$ \\
\hline $\begin{array}{l}\text { Nayent. } \\
\text { Thoret. }\end{array}$ & $\begin{array}{l}30 \text { ans. } \\
23 \text { ans. } \\
27 \text { ans. }\end{array}$ & $\begin{array}{c}\begin{array}{c}\text { Fievre } \\
\text { Euro- } \\
\text { peenne. }\end{array} \\
\text { idem. } \\
\text { idem. }\end{array}$ & $\begin{array}{c}\text { un an. } \\
6 \text { semaines. } \\
6 \text { semaines. }\end{array}$ & $\begin{array}{l}6 \text { jours. } \\
60 \text { heures. } \\
4 \text { jours. }\end{array}$ & $\begin{array}{c}\text { Vomisse- } \\
\text { ment noir, } \\
\text { hémor- } \\
\text { rhagie na- } \\
\text { zale et } \\
\text { alvine. } \\
\text { idem idem } \\
\text { idem. } \\
\text { Vomisse- } \\
\text { ment noir, }\end{array}$ \\
\hline
\end{tabular}

The above returns have been furnished by $\mathrm{Mr}$. Cheros, a French surgeon, employed by the British government, in the colonial duties of the Port at Basse Terre, Guadaloupe. His opportunities of information were limited, his practice not being extensive; but his education is good, and he stated that he had himself seen all the cases detailed. He calls the fever that of the Europeans, the name commonly given to the yellow fever in Guadaloupe. His return for the month of June has been mislaid.

Signed,

W. Fergusson,

Inspector of Hospitals. 


\section{APPENDIX X.}

Report from Assistant Surgeon RaLpH, of the 2d, or Queen's Regiment, on the Difference of Health between the upper and lower Stories of the Barracks occupied by that Corps.

"6 By a calculation made from the above Table, it appears that in the month of August, one case of fever presented itself in every twentieth man of those quartered on the ground-floor, and in each thirtieth man of those on the upper-floor. During that part of the month of September, which has elapsed, each treenty-fourth man was attacked with fever of those stationed in the upper rooms, and each fourteenth among those in the lower."

Signed,

A. J. RALPH. 


\section{APPENDIX XI.}

Comparative Sick Return of White Soldiers employed as Orderlies, in the General Hospital at Barbadoes, from the 25th of June, to the 24th of October, 1816.

\begin{tabular}{|c|c|c|c|c|c|}
\hline $\begin{array}{c}\text { Number of } \\
\text { Orderlies } \\
\text { employed } \\
\text { during the } \\
\text { period. }\end{array}$ & $\begin{array}{c}\text { Number } \\
\text { taken ill } \\
\text { of fever. }\end{array}$ & $\begin{array}{c}\text { Number } \\
\text { who died } \\
\text { of fever. }\end{array}$ & $\begin{array}{c}\text { Proportion } \\
\text { taken with } \\
\text { fever of the } \\
\text { number } \\
\text { employed. }\end{array}$ & $\begin{array}{c}\text { Proportion } \\
\text { of deaths } \\
\text { amongst } \\
\text { the } \\
\text { Orderlies. }\end{array}$ & $\begin{array}{c}\text { Proportion taken } \\
\text { with fever from } \\
\text { the total strength } \\
\text { amongst the troops } \\
\text { in garrison. }\end{array}$ \\
\hline 198 & 7 & 2 & $\begin{array}{c}\text { as } \\
1 \text { to } 28\end{array}$ & $\begin{array}{c}\text { as } \\
\text { to } 99\end{array}$ & 1 to 5 \\
\hline
\end{tabular}

N. B. It is ascertained that of the Orderlies dis- . charged by their own desire, or for misconduct, none came back as patients. One of those returned as having died from fever, was a very drunken character.

Signed,

A. Menzies,

Deputy Inspector of Hospitals. 


\section{APPENDIX XII.}

Extracts from the Reports of Staff Surgeon Lorssworth, P. M. O. of Grenada, on the State of the 15th Regiment, on their arrival there from Martinique, dated 12th and 20th of September, 1816.

"The 15th regiment have brought with them about seventy men as hospital patients, and nearly half the regiment as convalescents in barracks. I think I never saw a corps more dreadfully cut up from fever, I understand of the intermittent kind.

"We still continue with a heavy sick list, and to judge from the appearances of the men of the 15th regiment, I apprehend it will be some time before they recover, or our numbers in hospital diminish. This day we have in hospital one hundred and forty-four of that number, ninety-eight are of the 15th regiment, independent of a numerous convalescent list in barracks; indeed so debilitated are the men, that the slightest exertion or fatigue brings on relapses of fever, and sends them into hospital. I have therefore thought it adviseable to make a requisition for wine, as the ex. penditure for some time will probably be great."

Signed,

F. A. Loinsworth. 